\title{
O ESPORTE COMO ATIVIDADE COMPLEMENTAR CURRICULAR: UMA ANÁLISE A PARTIR DA TEORIA DO CAPITAL SOCIAL ${ }^{1}$
}

\author{
THE SPORTS AS COMPLEMENTARY CURRICULAR ACTIVITY: \\ AN ANALYSIS FROM THE THEORY OF SOCIAL CAPITAL
}

\author{
Eduard Angelo Bendrath \\ Doutor em Educaçáo pela Universidade Estadual Paulista. \\ Professor Adjunto da Universidade Estadual de Maringá - Campus Regional do Vale do Ivaí. \\ Ivaiporâ, Paraná, Brasil \\ ORCID: http://orcid.org/0000-0003-2980-4961 \\ eabendrath@uem.br
}

Andreia Paula Basei

Mestre em Educação pela Universidade Federal de Santa Maria. Professora Assistente da Universidade Estadual de Maringá - Campus Regional do Vale do Ivaí.

Ivaiporā, Paraná, Brasil ORCID: http://orcid.org/0000-0002-6675-6076 andreiabasei@yahoo.com.br

Resumo: As mudanças no cenário educacional nas últimas décadas têm fomentado novas perspectivas para a formulação e implementação de políticas públicas, pelas quais as políticas públicas educacionais gradativamente são orientadas para processos de ampliação da jornada escolar paliativos, pois são focadas em atividades complementares curriculares. $\mathrm{O}$ esporte, caracterizado como fenômeno social inserido no ambiente escolar, constitui um dos principais eixos articuladores de tais políticas. Assim, o objetivo deste trabalho é estabelecer os pressupostos teóricos do debate sobre as possibilidades que o esporte apresenta de fomentar as bases do capital social das comunidades escolares. Foram analisados os documentos que orientam a política de atividades complementares curriculares do estado do Paraná e concluiu-se que o esporte, enquanto açâo educativa poderia potencializar a acumulaçáo de capital social com base em princípios, normas e valores específicos de grupos sociais com interesses comuns.

Palavras-chave: Atividades Complementares Curriculares. Capital Social. Esporte.

Aвstract: The changes in the educational scene in recent decades has fostered new perspectives for the formulation and implementation of public policies. Thus, the public policies of education gradually are geared for process of expansion of the extension school day palliative with a focus on curricular activities complement. The sport characterized as a social phenomenon inserted into the school environment is therefore one of the main articulators of such policies. Thus, the objective of this study was to establish connections 
with theory and discuss the possibilities of sport in promoting the foundations of the social capital of school communities. We analyzed the documents that guide the policy of curricular activities complement within the state of Paraná and concludes that the sport while educational action could boost the accumulation of social capital in principles, norms and specific values in social groups with common interests.

Keywords: Curricular Activities Complement, Social Capital, Sports.

\section{Introduçáo}

Com a democratização do acesso à educação, a busca pela melhoria da qualidade educacional tornou-se o foco das açôes e das políticas públicas do setor no país. Açóes com vistas à implementação de novas práticas no ambiente escolar tornaram-se rotineiras no intento de ampliar as possibilidades educacionais.

Dentre tais proposituras, as atividades de contraturno escolar ganharam força e destaque pelo fato de se ajustarem especificamente às demandas das comunidades locais, uma vez que podem ser capazes de suprir as necessidades extracurriculares das crianças e adolescentes, favorecer um melhor aproveitamento do tempo ocioso delas e oportunizar aos pais um espaço diferenciado para seus filhos frequentarem durante o período em que estão trabalhando; além disso, potencializam o rendimento escolar e a formação por estarem envolvidos com atividades diversificadas nos âmbitos esportivo, de lazer e da cultural social.

Essa ampliaçáo da jornada escolar também está prevista na Lei de Diretrizes e Bases da Educação Nacional, em seu artigo 34, quando preconiza o gradativo aumento do tempo de permanência na escola para sete horas diárias, caracterizando-se, dessa forma, a educação de tempo integral (BRASIL, 1996). A proposta de ampliaçáo do tempo escolar evidencia uma intencionalidade formativa que percebe crianças e adolescentes em seus aspectos multidimensionais, ou seja, que busca desenvolver, incentivar e valorizar todas as possibilidades de enriquecimento cognitivo, cultural e social, explorando e integrando a escola com outras dimensóes da vida humana, das quais destacamos, neste artigo, o esporte.

O esporte, nessa perspectiva, figura como um elemento articulador de propostas, uma vez que a sua inserção enquanto prática e fenômeno sociocultural entre jovens é elemento facilitador na comunidade escolar. De 
acordo com a UNESCO (2015), esporte e educação física são essenciais para a juventude, para vidas saudáveis, para sociedades resilientes e para combater a violência. É assim que o esporte pode ser entendido como

[...] um fenômeno sociocultural, cuja prática é considerada direito de todos, e que tem no jogo o seu vínculo cultural e na competição o seu elemento essencial, o qual deve contribuir para a formação e aproximação dos seres humanos ao reforçar o desenvolvimento de valores [...] (TUBINO, 2010)

Da mesma maneira, Kunz (2004) dialoga no sentido de referendar as possibilidades educativas amplas do esporte, que se figura no que ele denomina "mundo vivido", e implica tematizar e compreender o fenômeno esportivo a partir de todas as suas interfaces, sejam elas biológicas, culturais, sociais, históricas e econômicas. Já para Manuel Sérgio (2003, p. 52), o esporte educacional possui papel importante quando se trata de renovação e transformação dos indivíduos, já que, o mesmo há de ser uma atividade instauradora e promotora de valores.

As atividades complementares curriculares com foco no esporte tenderiam, portanto, a se constituir como atividades dotadas de açóes programáticas próprias, com um viés orientado para as necessidades e anseios locais. Assim, apoiamo-nos nos princípios estabelecidos a partir da força das relaçôes sociais que o esporte pode propiciar, juntamente com os vínculos recíprocos e a confiança coletiva, bases essas que podemos compreender como princípios da teoria do capital social. De acordo com Ferlander (2007), nas últimas décadas o termo capital social vem sendo utilizado nas ciências sociais, particularmente nas áreas da sociologia, economia e educação, com a difusão da ideia de que as redes e as interaçóes sociais possuem valor e que a forma como esses vínculos são estabelecidos afetam diretamente os grupos de indivíduos.

Partindo dessa premissa, objetivamos neste texto analisar a partir de suas concepçóes propositivas, como a política educacional paranaense de implantação de atividades complementares curriculares em seu macrocampo esporte e lazer, se configura tendo como pano de fundo as bases que fundamentam os princípios do capital social. Recorremos a uma análise teórica com base em pesquisa documental a partir da proposta de 
atividade complementar curricular da Secretaria de Estado da Educação do Paraná e a observamos a partir da relação entre o esporte enquanto fenômeno sociocultural e a cadeia de relaçôes sociais e potencialidades educativas que apresenta.

\section{O capital social e o esporte}

O conceito de capital social começou a ganhar visibilidade no debate acadêmico e político a partir das proposiçóes apresentadas por Bourdieu (1985) e Coleman (1988), e se intensificou com os estudos de Putnam (2006) e Fukuyama (2002).

Apesar de os conceitos se aproximarem em termos de análise da realidade social, as posiçóes de Bourdieu e Coleman se mostram divergentes em determinados pontos. Para Bourdieu (1985) o capital social é definido pelos elementos baseados nas redes de relacionamentos sociais, bem como na quantidade e qualidade de recursos dos grupos de indivíduos. Segundo o autor, o reconhecimento das relaçóes e o fortalecimento dos vínculos entre os atores sociais não são provenientes apenas dos fatores econômicos e sociais, mas também do reconhecimento de valores simbólicos que asseguram o status de valoração e conexão a um determinado grupo. Dessa forma, segundo o autor, o capital social depende de quanto um indivíduo consegue em termos de mobilizaçáo da sua rede de relacionamentos para promover a troca de diferentes tipos de capital, seja econômico, cultural ou simbólico. Nesse sentido, a acumulaçáo de capital social dependeria da posição do sujeito dentro do próprio campo social, noção esta que faz menção a um espaço de correlaçóes de forças, lutas e conflitos onde os atores sociais utilizam diferentes estratégias e recursos para alcançar seus fins a partir de seus próprios interesses.

No entanto, para Coleman (1988), o conceito de capital social é definido pela sua função, ou seja, ele se configura como uma variedade de açóes que resulta em como estruturas sociais se estabelecem junto a um determinado grupo. Ainda segundo o autor, o capital social é dependente da estrutura e do contexto de indivíduos ou grupos pelos quais o valor que detêm é dado pelo aspecto da estrutura social, que por sua vez atua como recurso que os atores podem utilizar para alcançar seus objetivos 
(CAZELLI, 2005). O autor referenciado destaca que enquanto Bourdieu enfatiza os conflitos e as lutas concorrenciais entre indivíduos e grupos pelos diferentes espaços de poder, Coleman ressalta os meios pelos quais os diferentes grupos sociais trabalham em conjunto e as relaçôes de reciprocidade e confiança entre seus membros. Dessa forma, a proposição central do conceito parte da premissa de que determinado conjunto de normas, valores e características sociais estabelecem conexôes entre sujeitos com objetivos que tendem a ser partilhados, fortalecendo vínculos a um grupo cujos sujeitos são dotados de características comuns, perceptíveis a todos os membros.

Sua definição pode ser interpretada a partir de diferentes abordagens. Assim, para Fukuyama (2002), o capital social é composto de normas compartilhadas ou valores que promovem a cooperaçáo social, instanciadas em relacionamentos sociais reais, enquanto Putnam (2006) aponta que o capital social se fundamenta nas estruturas de confiança, solidariedade e reciprocidade entre indivíduos.

Sobre tais perspectivas, Portes (2000) assevera que as redes sociais não são um dado natural, tendo de ser construídas por meio de estratégias de investimento orientadas para a institucionalização das relaçôes do grupo, utilizáveis como fonte digna de confiança para ascender a outros benefícios. Nessa perspectiva, as redes de relacionamento e suas normas sociais são criadas a partir de diferentes contextos de engajamento social em que a participação cívica e a interação predispóem um ambiente que pode proporcionar o estabelecimento de vínculos de reciprocidade e confiança (TONTS, 2005). O capital social é o que permite que os indivíduos se reúnam para defender seus interesses e para se organizar no apoio a necessidades coletivas. (FUKUYAMA, 2002)

De acordo com Putnam (2000), a consolidação do capital social pode se dar por dois vieses: um denominado de 'ligação', e outro, pelo que ele denomina de 'ponte'.

O capital social como ligação estaria vinculado a redes sociais fechadas e reforçaria identidades exclusivas em grupos homogêneos. O esporte, principalmente os de natureza coletiva, estaria, portanto, suscetível à criação de fortes vínculos sociais, cujas características de organização, objetivos e perspectivas potencializariam as estruturas de confiança, solidariedade e reciprocidade internas dos indivíduos. 
Por outro lado, a heterogeneidade e as diferenças entre grupos e indivíduos não devem ser ignoradas. $\mathrm{O}$ autor argumenta que o capital social pode atuar como ponte, que apesar de mais frágil enquanto vínculo social se refere ao envolvimento e à disponibilizaçáo de recursos e oportunidades de um grupo a outro. Assim, o esporte figuraria como facilitador do entendimento da natureza humana em razão de suas múltiplas relaçôes, podendo ser usado para promover novas conectividades sociais que atravessam fronteiras de classe, religiáo, etnia etc. No entanto, a vinculação a fatores que propiciam unicidade coletiva e a valoração de normas comuns, tendo o esporte como pano de fundo, podem, em alguns casos, propiciar que o capital social esteja relacionado a casos de racismo, exclusão social e corrupção. (TONTS, 2005)

Para Putnam (2000), o capital social pode trazer elementos positivos e negativos na solidificação das estruturas sociais; porém, o autor argumenta que a baixa sociabilidade e a ascensão da televisão como forma dominante de lazer têm feito com que as ligaçóes e pontes relativas à constituição do capital social passem por um grave processo de erosão. Ainda segundo o autor, o esporte pode unir as pessoas num sentimento de orgulho, propósito comum e compromisso.

Considerado em seu aspecto pedagógico, o esporte se torna ferramenta fundamental para a valorizaçáo do ambiente escolar e do sentimento de pertencimento, fatores esses que podem estimular o processo de escolarização formal. Políticas educacionais orientadas para a valorização do esporte no ambiente escolar podem servir como fator de controle social ao mesmo tempo interno (comunidade escolar) e externo (comunidade local), pois possuem forte apelo o que favoreceria o princípio do engajamento coletivo.

Nesse sentido, Skinner, Zakus e Cowell (2008) apontam que os controles sociais são encontrados em estruturas sociais modernas e atividades participativas como o esporte, e dão sentido de identidade e propósito à comunidade, desse modo ajudando a impedir que os indivíduos se engajem em atividades antissociais. Já Cairnduff (2001, apud SKINNER; ZAKUS; COWELL, 2008) sugere que o esporte pode ajudar a criar comunidades com elevados níveis de capital social positivo e, desse modo, podem torná-las mais resistentes a resultados negativos de mudanças econômicas, sociais e culturais. 
Estudo de Delaney e Keaney (2005) no Reino Unido mostrou correlaçóes positivas entre esporte e capital social. Segundo as autoras, existe correlação entre a adesão à prática esportiva e os níveis de confiança e bem-estar; embora a correlação com a confiança nas instituiçóes se apresentasse bem mais fraca do que em relação aos outros dois fatores, os dados indicaram que o envolvimento com o esporte impacta positivamente na construção do capital social.

Tonts (2005) argumenta, porém, que não se deve romantizar o papel do esporte, uma vez que desigualdades e divisóes sociais podem ser fomentadas no ambiente esportivo, mesmo que muitas vezes tais comportamentos estejam associados a resultados negativos de capital social. Sobre essa questão, Putnam (2006) reconhece que algumas formas e relaçóes sociais podem inibir o estabelecimento de ligaçóes mais amplas e diversificadas, o que poderia estar também associado ao que Bourdieu (1985) aponta sobre as disputas concorrenciais entre indivíduos e grupos sociais que afetam diretamente o capital social.

\section{O esporte como atividade complementar curricular no âmbito escolar}

A implementação de projetos esportivos na perspectiva de ampliação da jornada escolar denota o entendimento da escola sobre a importância do papel do esporte no processo de construção de uma identidade coletiva, desenvolvendo ou aprimorando, além de competências técnicas, as sociais e comunicativas, fundamentais para uma formação emancipatória.

Esse posicionamento é fortalecido quando as atividades complementares curriculares estáo em consonância com os anseios da comunidade local. Skinner, Zakus e Cowell (2008) destacam que as comunidades são marcadas por laços profundos que muitas vezes envolvem um alto grau de intimidade pessoal, compromisso moral, coesão e continuidade no tempo. Ainda segundo esses autores, o esporte pode fornecer um caminho para o desenvolvimento pessoal contínuo, sendo o engajamento o indicador de sucesso. Dessa forma, o esporte poderia ser um veículo importante na constituição do capital social. 
Sob esse entendimento, a utilização de projetos paralelos ao sistema formal de ensino da educação básica não é novidade, mas tem ganhado destaque na última década em decorrência da possibilidade de melhoria da educação por meio do fortalecimento de vínculos entre escola e comunidade, bem como por tratar-se de um meio para se obter reforço escolar em áreas críticas do processo ensino-aprendizagem, contribuindo também para a melhoria dos indicadores educacionais.

Com inúmeras experiências dessa natureza no país, optamos por compreende-las melhor pelo estudo da dinâmica ocorrida no estado do Paraná, nas escolas vinculadas à Secretaria de Estado da Educação (SEED).

No estado do Paraná, tal perspectiva institucionalizou-se a partir de uma política pública formulada e implementada no ano de 2011 denominada Programa Atividades Complementares Curriculares (ACCs) da SEED, que objetiva proporcionar aos alunos da rede estadual a possibilidade de ampliaçáo da jornada escolar em atividades organizadas em 9 macrocampos: 1) Aprofundamento da Aprendizagem, 2) Experimentação e Iniciação Científica, 3) Cultura e Arte, 4) Esporte e Lazer, 5) Tecnologias da Informação, Comunicação e Mídias, 6) Meio Ambiente, 7) Direitos Humanos, 8) Promoção de Saúde, 9) Mundo do Trabalho e Geração de Renda (PARANÁ, 2011). Cada um desses macrocampos possui uma ementa própria e a indicação de inúmeras atividades possíveis de serem desenvolvidas; entre esses macrocampos, o de maior abrangência em termos de diversidade são os de Esporte e Lazer e Cultura e Arte.

Esse programa de contraturno escolar foi instituído na rede estadual de ensino, em caráter permanente, por meio da Resolução 1.690, de 27 de abril de 2011, da Secretaria Estadual de Educação (PARANÁ, 2011) e regulamentado pela Instruçáo Normativa n. 007/2012-SEED/ SUED (PARANÁ, 2012). Dentre as múltiplas possibilidades e alternativas de projetos a serem ofertadas no âmbito das ACCs, o esporte figura com destaque, tanto pela flexibilidade e diversidade de modalidades que podem ser ofertadas quanto por seu apelo e engajamento junto a crianças e adolescentes.

Em estudo realizado em escolas de cidades com mais de 100.000 habitantes no Paraná, Basei, Bendrath e Menegaldo (2017) identificaram que o macrocampo esporte e lazer detem um $1 / 3$ de todas as atividades executadas, e em termos absolutos $64,9 \%$ das atividades desse macrocam- 
po se resumem aos projetos de futsal, vôlei, atletismo, múltiplas vivências esportivas e tênis de mesa. Assim, se considerarmos que se trata apenas de um macrocampo, dentre 9 possíveis, é perceptível o quão significativo é o esporte para crianças e adolescentes e o quanto pode potencializar o estabelecimento de vínculos entre eles, com a comunidade e com o contexto social mais amplo. Estudo realizado por Luguetti et al (2013), na cidade de Santos, também mostrou que o esporte é entendido como uma política diretiva para aumento da jornada escolar. O objetivo é ampliar o tempo de permanência dos alunos das unidades municipais de ensino em atividades educativas nas áreas de cultura, artes e esportes (LUGUETTI et al, 2013).

Perspectivas dessa natureza já ocorrem também no nível federal, por meio de políticas públicas como Programa Segundo Tempo, Escola Aberta, Mais Educaçáo e Jogos Escolares Brasileiros. Seja como protagonista da atividade fim (Programa Segundo Tempo, Jogos Escolares Brasileiros) seja como atividade meio (Programa Escola Aberta e Mais Educação), o esporte figura no papel principal de facilitador de engajamento social em favor da educação.

$\mathrm{Na}$ proposta da Secretaria de Estado da Educação do Paraná (SEED), as atividades de ACCs são educativas e integradas ao currículo escolar, com a ampliação de tempos, espaços e oportunidades de aprendizagem que visam ampliar a formação do aluno (PARANÁ, 2012). As atividades podem ser desenvolvidas a partir de um caráter permanente, com a atribuição de 16 horas semanais distribuídas em 5 dias da semana para um mesmo grupo de alunos, ou de caráter periódico, com 4 horas de atividades semanais para determinado grupo de alunos. Ainda de acordo com a SEED, as atividades devem privilegiar indivíduos em situação de risco social, fator que ressalta a importância do esporte e sua capacidade de desenvolver competências entre seus participantes que busquem uma formação crítica, participativa e inclusiva junto ao grupo.

$\mathrm{Na}$ perspectiva posta pela SEED, cumpre observar o posicionamento de Skinner, Zakus e Cowell (2008, p. 256), que ressaltam que

O conceito de capital social ganhou destaque como um meio de entender como as comunidades podem operar para se tornarem mais seguras e mais produtivas e serem vistos como lugares onde identidades e estilos de vida positivos podem ser forjados. 
A segurança e a produtividade das comunidades também estão associadas ao que Bourdieu (1985) define como ganhos obtidos pelos indivíduos pela participação nos grupos. Segundo o autor, a participação nesses grupos permite aos indivíduos se apropriarem de benefícios materiais e simbólicos que partilham os seus membros. Dada a importância do esporte como mecanismo educativo que pode, dentre outros fatores, atuar na socialização, no desenvolvimento de habilidades e competências, bem como promover a saúde, pode-se compreende-lo como elemento facilitador do processo de tomada de decisão para a implantação dos projetos nas escolas. (BASEI; BENDRATH; MENEGALDO, 2017).

Tendo em vista serem objetivos da proposta a maior integraçáo entre alunos, escola e comunidade, e a democratização do acesso ao conhecimento e aos bens culturais (PARANÁ, 2012), ela se configura como meio de ampliar a participaçáo social no ambiente escolar. Mesmo que essa participaçáo seja limitada, ela pode proporcionar a todos os atores o seu reconhecimento como elemento fundamental na tomada de decisóes coletivas e nos próprios rumos que tomam as açóes do projeto.

Observando os preceitos de Bourdieu (2013), podemos compreender que o fator educacional, nesse caso, seria um ativo individual que possibilitaria assegurar a diferença entre indivíduos potencializando a cada um a captação de outras fontes de capital, em termos econômicos, culturais e simbólicos, a partir da rede de relacionamentos e suas influências. Já Coleman (1988) entende que o fator educacional está associado aos conceitos de expectativas e obrigaçóes presentes no capital social, pois influencia os indivíduos a partir da premissa das informaçôes, das normas e das condutas aceitas coletivamente dentro de um sistema de trocas voluntárias de compensaçôes (sejam elas econômicas, de status, poder etc.)

Dessa forma, o esporte abordado como macrocampo facilitador desse processo poderia contribuir para uma educação que vai além do movimento técnico humano e das regras desportivas. Como aponta Reis et al (2015), o esporte educacional muitas vezes aparece justaposto a outras questôes inerentes a escola, como a própria educação física e as competiçôes escolares. Skinner, Zakus e Cowell (2013) argumentam, nesse sentido, que o esporte pode ser um mecanismo para se envolver a partir de uma abordagem integrada e coordenada com uma política que reconhece o papel de todos os níveis de organizaçóes comunitárias do governo e do 
setor desportivo tradicional. Estamos falando, portanto, da participação social, do engajamento e dos valores relacionados ao princípio democrático do indivíduo, sejam valores para manutenção sejam eventuais mudanças, e mesmo para o aprendizado das formas de convivência social que são partilhadas pelos indivíduos.

Essa perspectiva também é posta por Seippel (2008), que aponta a criaçáo das redes de relacionamentos pautadas em valores recíprocos e participaçáo coletiva como criadoras e difusoras potenciais do capital social, tendo o esporte como eixo articulador. Para o autor, o conceito de capital social representa uma abordagem frutífera para entender como as redes sociais podem assumir forma e funçáo no caso do esporte. $O$ esporte seria, portanto, um facilitador da configuração de uma estrutura de organização social involuntária.

O objetivo proposto pela SEED para as ACCs é promover a melhoria da qualidade do ensino por meio da ampliação de tempos, espaços e oportunidades educativas realizadas em contraturno, respondendo às demandas educacionais e os anseios da comunidade (PARANÁ, 2012). Essa perspectiva é posta em paralelo à gradual expansão do tempo escolar da rede pública estadual paranaense (PARANÁ, 2011). Embora não seja conceitualmente tratado, nas diretrizes do Programa, por aquilo que se entende como educação integral verificamos nos documentos que essa concepção está fundamentada nos documentos do Ministério da Educação, o qual estabelece que a mesma.

[...] representa a opção por um projeto educativo integrado, em sintonia com a vida, as necessidades, possibilidades e interesses dos estudantes. Um projeto em que crianças, adolescentes e jovens são vistos como cidadãos de direitos em todas as suas dimensôes. Não se trata apenas de seu desenvolvimento intelectual, mas também do físico, do cuidado com sua saúde, além do oferecimento de oportunidades para que desfrute e produza arte, conheça e valorize sua história e seu patrimônio cultural, tenha uma atitude responsável diante da natureza, aprenda a respeitar os direitos humanos e os das crianças e adolescentes, seja um cidadão criativo, empreendedor e participante, consciente de suas responsabilidades e direitos, capaz de ajudar o 
país e a humanidade a se tornarem cada vez mais justos e solidários, a respeitar as diferenças e a promover a convivência pacífica e fraterna entre todos. (MEC, 2016)

Com essas premissas, é possível notar que se trata de uma questão complexa e de grande responsabilidade, uma vez que procura integrar todos os atores, náo somente os do processo educacional, mas também os atores sociais.

Com o posicionamento do esporte como macrocampo facilitador no direcionamento de projetos em contraturno escolar, a política de ACCs associa os requisitos de ligação direta do projeto político-pedagógico da escola previsto na sua resolução de criação (PARANÁ, 2012) com as possibilidades proporcionadas por atividades esportivas de interesse local que, em sua essência, estariam favorecendo a construção do capital social. São dois os fatores que corroboram para isso. $\mathrm{O}$ primeiro diz respeito à conectividade e interaçôes em linha horizontal, ou seja, grupos que compartilham traços comuns e características sociais conjuntas. O segundo faz menção à prática do esporte como fator de bem-estar individual voluntário. Tais fatores estariam associados à constituiçáo de confiança e engajamento, elementos fundamentais do capital social.

Dessa forma, observando a constituição do macrocampo proposto pela política de ACCs da SEED, as açôes que deveriam estar atreladas ao binômio Esporte e Lazer se orientam para uma diretiva única, com forte apelo para o esporte em detrimento do lazer. A criação de vínculos sociais por meio de açóes coletivas, cujos valores, normas e condutas tendem a se padronizar em um ambiente em que vários indivíduos partilham das mesmas aspiraçóes, tende a ser mais encorajado quando a prática é orientada para o esporte.

Para Basei, Bendrath e Menegaldo (2017), a prevalência do esporte em um macrocampo do qual também faz parte o lazer é inegável e absoluto, relegando um papel de coadjuvante para projetos cujas características orientam-se por valores e diretrizes associadas ao campo do lazer como prática possível na escola pública.

Para além da constituiçáo de capital social por meio do esporte em atividades complementares curriculares, a sua utilização como fator de desenvolvimento econômico e social, tanto de indivíduos quanto de grupos 
sociais, ainda é desconhecido. Seippel (2008) argumenta que a influência do esporte na sociedade civil depende de uma quantidade bem desenvolvida e equilibrada dos dois tipos de capital social: o de ligação e o de ponte. Segundo o autor, os esportes não proporcionam uma forte estrutura de oportunidade, de comunicação e de persuasão por si só, portanto, não têm uma condição prévia importante para uma posição realmente influente na sociedade civil. Assim, sua efetividade estaria muito mais suscetível ao estabelecimento de uma ponte com outras formas de organização social. Esse parece ser o mesmo entendimento de Tonts (2005), que indica que o capital social não é um conceito estático e imutável, sendo variável no espaço e no tempo de acordo com as condiçóes encontradas.

Essa ponte, portanto, poderia ser facilitada quando a participação é estimulada e as indicaçóes e objetivos das propostas partem da própria comunidade. Ao esporte cabe o papel de geração de vínculos participativos concretos, fator mais complexo de se obter em atividades de aprendizagem cujo foco centra-se no sujeito e não no grupo.

A participação nessas atividades decorre do fator motivacional, uma vez que não são obrigatórias dentro do regime seriado da escola, cabendo ao aluno optar tanto pela participação quanto pelas atividades que deseja realizar. Ao optar voluntariamente pela participação em determinada atividade o aluno incita uma conduta de ação que dá sentido à sua escolha. Sua participação não é neutra e desprovida de recursos, uma vez que talento, energia, conhecimentos e habilidades são investidos e compartilhados no grupo. Tal compreensão caminha no sentido de corroborar com os posicionamentos de Bourdieu (2013) sobre a ausência de neutralidade na educação, que seria proveniente apenas da composição de interesses coletivos postos a partir dos desejos da comunidade escolar, ou seja, como uma manutenção e reprodução de valores, preferências e aptidóes socialmente constituídos e reproduzidos historicamente pela escola.

Em se tratando do macrocampo Esporte e Lazer, a representatividade pela participação nas atividades tem uma significância maior, pois a Instrução Normativa no7/2012 da SEED coloca o macrocampo como de caráter eletivo em relação a outros, como pode ser observado no Quadro 1.

Observando as proposiçôes da Instrução Normativa, fica explícita a intencionalidade do Programa de melhoria dos indicadores de qualidade educacional, uma vez que o foco principal do macrocampo obrigatório, o 


\begin{tabular}{|c|}
\hline Macrocampo Obrigatório \\
\hline Aprofundamento da Aprendizagem \\
\hline Macrocampos Prioritários \\
\hline Experimentaçáo e Iniciação Científica \\
\hline Direitos Humanos \\
\hline Meio Ambiente \\
\hline Promoçáo da Saúde \\
\hline Macrocampos Eletivos \\
\hline Cultura e Arte \\
\hline Mundo do Trabalho e Geração de Rendas \\
\hline Tecnologia da Informação, Comunicaçáo e uso de mídias \\
\hline Esporte e Lazer \\
\hline
\end{tabular}

\section{Quadro 1: Estrutura da Política de ACCs}

Fonte: Instrução Normativa 07/2012 SEED/PR.

aprofundamento da aprendizagem, é uma espécie de reforço das disciplinas curriculares obrigatórias, contemplando a sustentabilidade socioambiental, os cuidados com a saúde e a formação cidadã voltadas à liberdade e aos direitos, sendo todas temáticas que de alguma forma são abordadas no currículo formal. Esses aspectos podem ser percebidos de forma contraditória aos interesses da comunidade escolar, pois como citado acima em pesquisa realizada nos municípios de grande porte do Estado, o macrocampo Esporte e Lazer figura com maior relevância frente ao macrocampo obrigatório e/ou prioritário.

Essa questáo deve ser observada de modo muito cuidadoso quando se trata de consolidar uma política cujos objetivos estáo voltados para a construção do capital social, pois o Programa não pode ficar limitado a oferecer mais do mesmo, mas sim configurar novos arranjos pedagógicos para efetivamente ampliar as oportunidades e experiências de aprendizagem dos alunos. Observamos na proposta a intencionalidade de difundir a necessária ocupação dos espaços públicos como uso de todos e para todos, enaltecendo uma formação cidadá, para além de algo que se constitui como direito civil e social.

Ao elencar a possibilidade de debate e voz nas escolhas relativas às ACCs pela comunidade local na escola, juntamente com a possibilidade 
de as atividades extrapolarem os muros limítrofes do ambiente escolar, a proposta da SEED parece ter como objetivo valorizar e reforçar os aspectos de cidadania local a partir do princípio de comunidade cívica. Para Putnam (2006), comunidade cívica diz respeito a associaçóes de indivíduos que pensam da mesma forma e contribuem para um governo democrático e eficaz. Para o autor, certas estruturas e práticas sociais incorporam e reforçam normas e valores que dizem respeito aos postulados de uma comunidade cívica. Nesse contexto, a escola enquanto espaço social de compartilhamento de diversas formas de capital figura como instituição que pode contribuir para a eficácia governamental a partir dos seus efeitos internos (no sujeito) e externos (na sociedade). Os sistemas de participação cívica, como associaçóes comunitárias, clubes esportivos e instituiçôes educacionais, representam uma intensa interação horizontal.

Os sistemas de participação cívica são uma forma essencial de capital social: quanto mais desenvolvidos forem esses sistemas numa comunidade, maior será a probabilidade de que seus cidadãos sejam capazes de cooperar em benefício mútuo. (PUTNAM, 2006, p. 183)

Para Dias (2005), numa comunidade cívica a cidadania se caracteriza primeiramente pela participação nos negócios públicos: o interesse e participação nas causas públicas são os principais sinais da virtude cívica. A comunidade cívica não está livre de conflitos, pois seus cidadãos têm opiniōes, mais ou menos firmes, sobre as questóes públicas. O capital social pode atuar como elemento integrador da comunidade cívica (capital social positivo) ou desagregador (capital social negativo, no qual imperam altas taxas de conflitos e insegurança institucional)

O posicionamento de Putnam (2006) sobre o conceito de comunidade cívica recai na constituição da própria base do capital social. Quanto maior for o capital social de uma sociedade, maiores seráo os princípios e valores partilhados como comunidade cívica. Apoiando-se nas premissas de Alexis de Tocqueville, enfatiza que uma comunidade cívica é amparada por princípios democráticos fundamentados na associaçáo entre liberdade e igualdade. Numa comunidade cívica, a cidadania se fortalece na fortalecimento dos pilares de direitos e deveres iguais a todos e se consolida a 
partir dos princípios de solidariedade, confiança e tolerância. (PUTNAM, 2006). Assim, a partir da objetivação da política de ACCs no Paraná, a constituição de comunidades cívicas nas escolas partiria pelo inexorável caminho de constituição do capital social local associado a valores fundamentais de democracia e humanismo.

Cabe observar, sobre essa proposta educativa, alguns fatores a serem ponderados com base nas premissas postas. As ACCs propostas pela política educativa da SEED caminham no sentido de valorizar a iniciativa local, os anseios locais e a participação coletiva, mas não há mecanismos que assegurem sua eficácia do ponto de vista diretivo. O capital social, nesse sentido, pode ser estimulado via participaçáo coletiva dentro do macrocampo Esporte e Lazer, com base em todos os pilares: confiança, solidariedade e reciprocidade.

A proposta da SEED para as ACCs possuem intencionalidades propositivas que se alinham com os princípios do capital social, o que poderia contribuir positivamente para a geração de uma comunidade cívica integrada com uma proposta educacional.

\section{Consideraçóes finais}

O esporte é um importante fator de integração social e está presente no ambiente escolar a partir dos conteúdos programáticos da Educação Básica, via componente curricular Educação Física. A ampliação das açôes a partir de atividades complementares curriculares se caracteriza como um reforço de açóes com vistas à melhoria da qualidade da educaçáo, proporcionando diversificadas experiências de enriquecimento cognitivo, cultural e social aos alunos e uma gradual ampliação da jornada escolar.

Atividades complementares curriculares com um viés voltado à prática esportiva podem proporcionar fatores que se relacionam com princípios de comunidade cívica, como a participaçáo social, o envolvimento com temas recorrentes ao interesse coletivo, bem como a solidariedade e reciprocidade fatores presentes no princípio da acumulação de capital social.

Nessa perspectiva, o capital social seria incentivado por um conjunto de elementos que instigaria nas comunidades a valorização dos aspectos 
de pertencimento, solidariedade e confiança, ampliando as possibilidades educacionais para além de conteúdos programáticos tradicionais. Dentro do contexto teórico do capital social, a denominação do que se conhece por redes sociais (grupos sociais coesos e que compartilham dos mesmos valores, normas e condutas), duradouras ou nâo, podem conduzir a um alto grau de engajamento e participação. A participação e geração de capital social pode favorecer a constituição de grupos coesos e orientados para interesses comuns, nesse caso as possibilidades de mudanças podem gerar ativos de capital social positivo e também negativo, conforme a própria literatura sobre o tema apresenta.

A proposta da SEED caminha para dar voz às comunidades escolares a fim de definir atividades vinculadas a macrocampos de interesse local. A gradual implantação de tais atividades nas escolas estaduais já é uma realidade e a observação dos resultados advindos dessa política é necessária para a compreensão da proposta do programa e futuramente das iniciativas envolvidas em cada comunidade escolar.

As bases que fundamentam a constituição do capital social, de fato, podem estar presentes em atividades complementares curriculares, e o esporte, de maneira especial, tem potencialidades maiores de geração de vínculos coletivos pela sua própria especificidade e natureza. $\mathrm{O}$ entendimento de tais princípios pode ser a peça fundamental para boa orientação e constituição de projetos que objetivem, não só a formação lúdica e esportiva, mas também a geração e manutenção de redes de relacionamentos sociais positivos e com viés de fortalecimento das comunidades cívicas.

\section{Nota}

1 A presente pesquisa recebeu recursos do CNPq, conforme processo 401984/2016-8

\section{Referências}

BASEI, Andréia Paula; BENDRATH, Eduard Angelo; MENEGALDO, Pedro Henrique Iglesiaz. Atividades complementares curriculares em contraturno escolar no estado do Paraná: um estudo do macrocampo esporte e lazer. Revista Motrivivência, Florianópolis, v. 29, n. 51, jun. 2017. doi: http://dx.doi.org/10.5007/45288. 
BOURDIEU, Pierre. The forms of capital. In RICHARDSON, J. G. (org.). Handbook of Theory and Research for the Sociology of Education, Nova Iorque, Greenwood, 1985, pp. 241-258.

BOURDIEU, Pierre. Escritos de educação. 14 ed. Petrópolis, RJ: Vozes, 2013.

BRASIL. Lei 9.394, de 20 de dezembro de 1996: Lei de Diretrizes e Bases da Educação Nacional. Senado Federal. Secretaria Especial de Editoração e Publicaçóes. Subsecretaria de Ediçóes Técnicas. Brasília. 1996.

CAZELLI, Sibele. Ciência, cultura, museus, jovens e escolas: quais as relaçóes? 2005. Tese (Doutorado em Educação) - Departamento de Educação, Pontifícia Universidade Católica do Rio de Janeiro. Rio de Janeiro, 2005.

COLEMAN, J. S. Social capital in the creation of human capital. The American Journal of Sociology, Vol. 94, Supplement: Organizations and Institutions: Sociological and Economic Approaches to the Analysis of Social Structure. 1988, pp. 95-120.

DELANEY, Liam; KEANEY, Emily. Sport and social capital in the united kingdom: statistical evidence from national and international survey data. Commissioned by the Department of Culture, Media and Sport. Londres, 2005.

DIAS, Rodrigo Araújo. Comunidade cívica: o círculo vicioso democrático da eficácia institucional. Org \& Demo, v. 6, n.1/2, 2005, pp.69-82.

FERLANDER, Sara. The importance of different forms of social capital for health. Acta Sociologica, v. 50, n. 2, 2007, pp.115-128.

FUKUYAMA, Francis. Social capital and development: the coming agenda. SAIS Review, v. 22, n. 1, Winter-Spring, 2002, pp. 23-37.

KUNZ, Elenor. Transformação didático-pedagógica do esporte. 6. ed. Ijuí: Unijuí, 2004, $160 \mathrm{p}$.

LUGUETTI, Carla Nascimento, et al. Práticas esportivas escolares na cidade de Santos-SP: o ponto de vista dos professores/treinadores. Revista Motriz. v.19, n. 1, 2013, pp.10-21.

MINISTÉRIO DA EDUCAÇÃO. Educação Integral. Brasília, 2016. Disponível em: http://educacaointegral.mec.gov.br/ Acesso em: 12 Dez 2017

PARANÁ. Secretaria do Estado da Educação. Superintendência da Educação. Instrução $n^{\circ}$ 007/2012-SEED/SUED. Dispóe sobre o Programa de Atividades Complementares Curriculares em contraturno, nas instituições de ensino da Rede Estadual. Paraná, 2012.

PARANÁ. Secretaria do Estado da Educação. Superintendência da Educação. Resolução 1.690 - 27 de Abril de 2011. Publicado no Diário Oficial no. 8472 de 24 de Maio de 2011. 
PORTES, Alejandro. Capital social: origens e aplicaçôes na sociologia contemporânea. Sociologia, problemas e práticas, n 33, 2000, pp. 133-158

PUTNAM, Robert D. Comunidade e democracia: a experiência da Itália moderna. 5. ed. Rio de Janeiro, Editora FGV, 2006, 260p.

PUTNAM, Robert D. Bowling Alone: The Collapse and Revival of American Community. 1.ed. New York, Simon \& Schuster, 2000, 544p.

REIS, Nadson Santana, et al. O esporte educacional como tema da produção do conhecimento no periodismo científico brasileiro: uma revisão sistemática. Revista Pensar a Prática, Goiânia, v. 18, n. 3, jul./set. 2015.

SÉRGIO, Manuel. Algumas teses sobre o desporto. Lisboa: Compendium, 2003.

SEIPPEL, Ornulf. Sports in civil society: networks, social capital and influence. European Sociological Review. v.24, n.1, 2008, pp.69-80

SKINNER, James; ZAKUS, Dwight H; COWELL, Jaqui. Development through sport: building social capital in disadvantaged communities. Sport Management Review, v.11, 2008, pp. $253-275$

TONTS, Matthew. Competitive sport and social capital in rural Australia. Journal of Rural Studies v. 21, 2005, pp.137-149.

TUBINO, Manoel José Gomes. Estudos brasileiros sobre o esporte: ênfase no esporteeducação. Maringá: Eduem, 2010.163 p.

UNESCO. Diretrizes em Educação Física de Qualidade (EFQ) para gestores de politicas. Brasília, UNESCO, 2015, 86 p.

Recebido em I4 jun. 2017 / Aprovado em 27 jan. 2019

Para referenciar este texto:

BENDRATH, E. A.; BASEI, A. P. O esporte como atividade complementar curricular: uma análise a partir da teoria do capital social. EccoS - Revista Científica, São Paulo, n. 48, p. 219-237. jan./mar. 2019. Disponível em: <https://doi.org/I0.5585/ EccoS.n48.7509>. 
